\title{
Mutation of $\operatorname{tag} \mathrm{O}$ reveals an essential role for wall teichoic acids in Staphylococcus epidermidis biofilm development
}

\author{
Linda M. Holland, Brian Conlon and James P. O'Gara \\ School of Biomolecular and Biomedical Science and Conway Institute of Biomolecular and \\ Biomedical Research, University College Dublin, Belfield, Dublin 4, Ireland
}

Correspondence

James P. O'Gara

jim.ogara@ucd.ie

Received 4 June 2010

Revised 24 September 2010

Accepted 2 November 2010

\section{INTRODUCTION}

Teichoic acids are a group of polyanionic cell surface molecules that have been implicated in maintaining cation homeostasis (Hughes et al., 1973; Lambert et al., 1977), anchoring of cell surface proteins (Navarre \& Schneewind, 1999), modulation of autolytic enzymes (Calamita \& Doyle, 2002; Schlag et al., 2010), and biofilm development (Gross et al., 2001). Staphylococci contain two types of teichoic acid, peptidoglycan-bound wall teichoic acids (WTA) and membrane-anchored lipoteichoic acids (LTA). WTA of staphylococci are mainly composed of ribitol phosphate groups, whereas LTA contain glycerol phosphate groups (Endl et al., 1983; Vinogradov et al., 2006). Cell surface teichoic acids can be further modified by the addition of positively charged D-alanine residues by the dltABCD operon (Gertz et al., 1999). A Staphylococcus aureus dltA mutant is unable to produce biofilm on polystyrene or glass. This phenotype has been attributed to

Abbreviations: BATH assay, bacterial adherence to hydrocarbon assay; eDNA, extracellular DNA; PIA, polysaccharide intercellular adhesin; WTA, wall teichoic acids.

A supplementary figure, showing growth curves of CSF41498 pLI50, TAGO1 pLI50 and TAGO1 pSETAG6 cultures, is available with the online version of this paper. a decrease in primary attachment and not accumulation, as levels of the extracellular polysaccharide polysaccharide intercellular adhesin (PIA) were unaffected (Gross et al., 2001). A loss of D-alanine residues on surface teichoic acids as a result of the $d l t A$ mutation may lead to an increase in the net negative charge of the cell surface increasing the strength of repulsive forces, which in turn prevents adherence of the bacteria to a surface. There is also evidence that alterations of the teichoic acid net charge in Bacillus subtilis may affect adhesive properties in an indirect manner, by causing changes in the folding of exo-proteins, thereby altering cell surface interactions (Hyyrylainen et al., 2000).

The composition of peptidoglycan-bound WTA varies among organisms and species, but the most common structures contain either glycerol phosphate (Gro-P) or ribitol phosphate (Rbo-P) repeating units (Neuhaus \& Baddiley, 2003; Swoboda et al., 2010). In Staphylococcus epidermidis RP62A, WTA are composed of Gro-P repeating units, substituted with glucose, galactose and $\mathrm{N}$-acetylated aminosugars, as well as D-alanyl, L-lysyl or acetyl residues (Sadovskaya et al., 2004). S. aureus WTA comprise two to three units of Gro-P followed by approximately 40 units of Rbo-P polymers substituted with D-alanine and $\mathrm{N}$ acetylglucosamine (Vinogradov et al., 2006; Weidenmaier 
\& Peschel, 2008). The tag (teichoic acid glycerol) genes were first identified and characterized in B. subtilis 168, which contains WTA composed of Gro-P repeating units (Mauël et al., 1991, 1995). The tagO gene encodes an enzyme responsible for the first step of WTA biosynthesis (Soldo et al., 2002). Studies of B. subtilis W23 and S. aureus which contain WTA composed of Rbo-P polymers have identified the tar (teichoic acid ribitol) genes, and functions have been identified for these genes based on sequence homologies to the tag genes (Brown et al., 2008; Lazarevic et al., 2002; Qian et al., 2006). Similar to B. subtilis 168 and W23, WTA biosynthesis in S. aureus begins with the $\operatorname{tag} O$ gene product, and deletion of $\operatorname{tag} O$ in $S$. aureus impairs WTA biosynthesis (Weidenmaier et al., 2004).

Although the icaADBC-encoded exopolysaccharide PIA or polymeric $\mathrm{N}$-acetylglucosamine (PNAG) is the best-characterized component of the $S$. epidermidis biofilm matrix (Heilmann et al., 1997; Mack, 1999), WTA also play an important structural role (Sadovskaya et al., 2004, 2005). Recent studies have also revealed the importance of extracellular DNA (eDNA) in the $S$. aureus and $S$. epidermidis biofilm matrix (Eckhart et al., 2007; Izano et al., 2008; Mann et al., 2009; Qin et al., 2007; Rice et al., 2007).
In this study the impact of an S. epidermidis tagO deletion mutation on biofilm development and biofilm-related phenotypes was investigated. Autolytic activity, eDNA release and PIA production were examined. Our findings reveal that $\operatorname{tagO}$ is required for $S$. epidermidis biofilm production. Furthermore, increased cellular aggregation by the $\operatorname{tag} O$ mutant involving eDNA and protein adhesins can mediate the formation of a pellicle which limits surface interactions.

\section{METHODS}

Bacterial strains, phage, plasmids, media and growth conditions. The bacterial strains and plasmids used in this study are listed in Table 1. Escherichia coli strains were grown at $37{ }^{\circ} \mathrm{C}$ on LuriaBertani (LB) medium (Sigma) supplemented when required with kanamycin, $50 \mu \mathrm{g} \mathrm{ml}^{-1}$; ampicillin, $50 \mu \mathrm{g} \mathrm{ml}^{-1}$; Bluo-gal, $200 \mu \mathrm{g}$ $\mathrm{ml}^{-1}$. Staphylococcal strains were grown at 37 or $30{ }^{\circ} \mathrm{C}$ on brain heart infusion (BHI) media (Oxoid). When required, BHI was supplemented with chloramphenicol $(\mathrm{Cm}), 10 \mu \mathrm{g} \mathrm{ml}{ }^{-1}$; tetracycline (Tet), $5 \mu \mathrm{g} \mathrm{ml}^{-1}$; Bluo-gal $200 \mu \mathrm{g} \mathrm{ml} \mathrm{m}^{-1}$. BHI was supplemented where indicated with $1 \%(\mathrm{w} / \mathrm{v})$ glucose. S. epidermidis phage $\mathrm{KC}$, a kind gift from Dr Tyrone Pitt, Laboratory of Healthcare Associated Infection, London, UK, was used in phage susceptibility assays, essentially as described elsewhere (Novick, 1991). Briefly, serial dilutions of tryptic soya broth (TSB) containing CSF41498 and TAGO1 cells harvested from $\mathrm{BHI}$ agar slants were mixed with phage $\mathrm{KC}$ and added to molten

Table 1. Strains and plasmids used in this study

\begin{tabular}{|c|c|c|}
\hline Strain or plasmid & Relevant characteristic(s) & Source or reference \\
\hline CSF41498 & Biofilm-positive, cerebrospinal fluid isolate & Conlon et al. (2002) \\
\hline TAGO1 & CSF41498 derivative, $\Delta \operatorname{tagO}:: \mathrm{Tc}^{\mathrm{r}}$ & This study \\
\hline RN4220 & Restriction-deficient derivative of S. aureus 8325 & Kreiswirth et al. (1983) \\
\hline E. coli $\mathrm{TOPO}$ & recA1 endA1 lac $\left[\mathrm{F}^{\prime}\right.$ proAB lac1q $\left.\mathrm{Tn} 10\left(\mathrm{Tc}^{\mathrm{r}}\right)\right]$ & Invitrogen \\
\hline pCR-Blunt II-TOPO & PCR cloning vector; $\mathrm{Km}^{\mathrm{r}}$ & Invitrogen \\
\hline pBT2 & Temperature-sensitive E. coli-Staphylococcus shuttle vector. $\mathrm{Ap}^{\mathrm{r}}$ (E. coli) $\mathrm{Cm}^{\mathrm{r}}$ (Staphylococcus) & Brückner (1997) \\
\hline pMAD & $\begin{array}{l}\text { Shuttle vector for allele replacement. Ap }{ }^{\mathrm{r}} \text { (E. coli) } \mathrm{Em}^{\mathrm{r}} \text { (Staphylococcus). Contains bgaB } \\
\text { gene encoding a thermostable } \beta \text {-galactosidase }\end{array}$ & Arnaud et al. (2004) \\
\hline pT181 & $4.45 \mathrm{~kb}$ S. aureus plasmid containing tet $A$ gene & Khan \& Novick (1983) \\
\hline pBT2:: bga & $\begin{array}{l}2803 \text { bp SmaI-SwaI fragment containing the } b g a B \text { gene from pMAD cloned into the } \\
\text { SmaI site of pBT2 }\end{array}$ & This study \\
\hline pSETAG2 & $\begin{array}{l}\text { Plasmid containing the deleted } \operatorname{tagO}(1021 \mathrm{bp}) \text { gene using the primers SEtagOdell and } \\
\text { SEtagOdel } 2 \text { with incorporated StuI enzyme sites }\end{array}$ & This study \\
\hline pSETAG3 & $\begin{array}{l}2236 \text { bp SwaI-SmaI fragment containing the tetA gene from pBlue: : tet cloned into the } \\
\text { StuI site of pSETAG2 }\end{array}$ & This study \\
\hline pSETAG4 & $\begin{array}{l}3921 \text { bp BamHI-XbaI fragment containing the } \Delta \operatorname{tagO}:: \mathrm{Tc}^{\mathrm{r}} \text { allele from pSETAG3 cloned } \\
\text { into the BamHI-XbaI sites of pBT2::bga }\end{array}$ & This study \\
\hline pSETAG5 & $\begin{array}{l}1978 \text { bp PCR product containing tagO amplified from CSF41498 using primers SEllm1 } \\
\text { and SEllm2 and cloned into pCR-Blunt II-TOPO }\end{array}$ & This study \\
\hline pSETAG6 & EcoRI fragment from pSETAG5 containing tagO cloned into pLI50 & This study \\
\hline
\end{tabular}


$\left(48{ }^{\circ} \mathrm{C}\right)$ soft agar before being poured onto TSB agar containing $5 \mathrm{mM} \mathrm{CaCl}_{2}$. The plates were incubated overnight at $37{ }^{\circ} \mathrm{C}$ and p.f.u. $\mathrm{ml}^{-1}$ was determined.

Detection of biofilm formation on Congo red agar. The morphology of staphylococcal isolates on Congo red agar (CRA) has been used to detect biofilm production and has been shown to correlate with a biofilm-positive phenotype (Handke et al., 2004). Biofilm-forming isolates produce black, dry colonies with irregular morphology on CRA. Biofilm-negative isolates produce smooth, red colonies. Single colonies were subcultured from BHI agar onto CRA containing $0.8 \mathrm{mg}$ Congo red $\mathrm{ml}^{-1}$ and $5 \%(\mathrm{w} / \mathrm{v})$ sucrose. Plates were incubated for $24 \mathrm{~h}$ at $37^{\circ} \mathrm{C}$ and a further $72 \mathrm{~h}$ at room temperature. Plates were examined after 48 and $72 \mathrm{~h}$ incubation at room temperature, and strains were noted to produce either black, dry colonies with irregular morphology (biofilm-forming colonies) or smooth, red, convex colonies.

Construction of an S. epidermidis tagO deletion mutant. The $S$. epidermidis CSF41498 tagO deletion mutant TAGO1 was constructed using the following procedure. A $2642 \mathrm{bp}$ fragment containing the tagO gene was amplified by PCR using Phusion high-fidelity DNA polymerase (NEB) and the primers tagO1 and tagO2 (Table 2), and was cloned into the pCR-Blunt II-TOPO plasmid (Invitrogen) to create pSETAG1. A $1021 \mathrm{bp}$ portion of the tagO gene was subsequently deleted by inverse PCR using Phusion high-fidelity DNA polymerase and the primers SEtagOdell and SEtagOdel2 containing StuI enzyme sites at the $5^{\prime}$ end (Table 2). The resulting PCR fragment was purified and digested with StuI, followed by religation to create pSETAG2. The $2236 \mathrm{bp} \mathrm{Tc}^{\mathrm{r}}$ gene was cloned from pBlue: tet on a SwaI-SmaI fragment and ligated into the StuI site to create pSETAG3. A 3921 bp BamHI-XbaI fragment containing the mutant allele from pSETAG3 was ligated into pBT2:: bga digested with BamHI/NheI to create pSETAG4. The temperature-sensitive pSETAG4 was electroporated into RN4220 and subsequently CSF41498.

The $S$. aureus $\operatorname{tag} O$ mutation results in a temperature-sensitive phenotype (Vergara-Irigaray et al., 2008); therefore, allele replacement was achieved using a variation of the normal heat-shock protocol. CSF41498 containing plasmid pSETAG4 was grown at $30{ }^{\circ} \mathrm{C}$ in the presence of $\mathrm{Cm}$ and Tet for $24 \mathrm{~h}$, followed by $6 \mathrm{~h}$ growth at $42{ }^{\circ} \mathrm{C}$ without antibiotic selection and selection of $\mathrm{Tc}^{\mathrm{r}}$ colonies on $\mathrm{BHI}$ agar plates. Bluo-gal, $200 \mu \mathrm{g} \mathrm{ml}^{-1}$ (Invitrogen), was included in the media to facilitate blue/white screening. A mixture of dark-blue and pale-blue colonies was observed following incubation for $24 \mathrm{~h}$ at $37{ }^{\circ} \mathrm{C}$. Dark-blue colonies presumably contain extra-chromosomal pSETAG4, whereas pale-blue colonies have undergone a single recombination event and have incorporated the entire plasmid onto the chromosome. Plasmid DNA was prepared from the pale-blue colonies and digested to confirm the loss of the extra-chromosomal pSETAG4. These colonies were then grown for several subcultures in BHI without antibiotic selection at $37{ }^{\circ} \mathrm{C}$ to encourage plasmid excision via a second recombination event. This was followed by selection of $\mathrm{Tc}^{\mathrm{r}}$ colonies on BHI agar plates containing $200 \mu \mathrm{g}$ Bluogal ml${ }^{-1}$. White, $\mathrm{Tc}^{\mathrm{r}}$ colonies were then screened for sensitivity to $\mathrm{Cm}$ to confirm plasmid loss, and PCR analysis was used to verify the presence of the mutant allele on the chromosome (data not shown).

To complement the tagO deletion mutant, a $1978 \mathrm{bp}$ fragment containing the S. epidermidis tagO gene was amplified from CSF41498 genomic DNA using Phusion high-fidelity DNA polymerase (NEB) and the primers SEllm1 and SEllm2 (Table 2), and was cloned into the pCR-Blunt II-TOPO plasmid (Invitrogen) to create pSETAG5. From pSETAG5 an EcoRI fragment containing the tagO gene was cloned into pLI50 to create pSETAG6.

Biofilm and pellicle formation assays. Semiquantitative measurements of biofilm formation under static conditions were determined using Nunclon tissue culture-treated ( $\Delta$ Surface) 96-well polystyrene plates (Nunc), as described previously (Conlon et al., 2002). Tissue culture-treated polystyrene is more negatively charged and hydrophilic than untreated polystyrene, which is hydrophobic. Each strain was tested at least three times and mean results are presented. A biofilm-positive phenotype was defined as $A_{492} \geqslant 0.17$.

Measurement of pellicle formation was performed using a modified biofilm assay in which the pellicle, which is defined here as an adherent mat of biomass only loosely attached to the polystyrene surface, was very gently washed to prevent its detachment from the plate prior to staining. In contrast, for biofilm measurements, the plates were vigorously washed three times by submersion in water. Vigorous washing caused the pellicle to rapidly detach and wash away.

Table 2. Oligonucleotide primers used in this study

\begin{tabular}{|c|c|c|}
\hline Target gene & Primer & Sequence $\left(5^{\prime}-3^{\prime}\right)$ \\
\hline \multirow[t]{2}{*}{$\operatorname{tag} O$ (for deletion of gene) } & $\operatorname{tagO1}$ & CССАCTGCACTGACAATACC \\
\hline & $\operatorname{tagO} 2$ & CGGTCATAACTGCAATCTTCA \\
\hline \multirow[t]{2}{*}{$\operatorname{tagO}$ (for inverse PCR) } & SEtagOdel1 & GAAGGCCTCAGTTCACCTTCATTGAA \\
\hline & SEtagOdel2 & GAAGGCCTTTTACTGGATTAATAGAT \\
\hline \multirow[t]{2}{*}{ tagO (full-length gene) } & SEllm1 & CGTTTTGAAATGGGATAGGG \\
\hline & SEllm2 & TAGGTGCAGGCGGTCTTATT \\
\hline \multirow[t]{2}{*}{$\operatorname{gyrB}$} & GYRB1 & TTATGGTGCTGGACAGATACA \\
\hline & GYRB2 & CACCGTGAAGACCGCCAGATA \\
\hline \multirow[t]{2}{*}{$i c a A$} & KCA1 & AACAAGTTGAAGGCATCTCC \\
\hline & KCA2 & GATGCTTGTTTGATTCCCT \\
\hline \multirow[t]{2}{*}{$i c a R$} & icaRFor2 & ATCCAAAGCGATGTGCGTAG \\
\hline & icaRRev2 & TCCATTGACGGACTTTACCAG \\
\hline \multirow[t]{2}{*}{ atle } & SEatlE_for & TTTGCAATTGGTGCATTTGA \\
\hline & SEatlE_rev & TACCAGGGTTTGCAGGATTC \\
\hline \multirow[t]{2}{*}{ aap } & AAP1 & AAAATTCACTGTTGGTACGG \\
\hline & AAP2 & AGAAGACATCTGTGGTGCTT \\
\hline
\end{tabular}


Primary attachment assays. Attachment assays using Nunclon tissue culture-treated ( $\Delta$ Surface) 96 -well polystyrene plates (Nunc) were carried out using overnight cultures adjusted to $\mathrm{OD}_{600} 1.0$ and exponential phase cultures $\left(\mathrm{OD}_{600}\right.$ 1.0). A $200 \mu \mathrm{l}$ volume of each suspension was used to inoculate the microtitre plate wells prior to incubation at $37{ }^{\circ} \mathrm{C}$ for $2 \mathrm{~h}$. Following incubation, the wells were washed gently three times with distilled $\mathrm{H}_{2} \mathrm{O}$, dried at $65{ }^{\circ} \mathrm{C}$ for $1 \mathrm{~h}$ and stained for $10 \mathrm{~min}$ with $0.4 \%$ crystal violet. After staining, the plates were washed gently three times with distilled $\mathrm{H}_{2} \mathrm{O}$ and the remaining crystal violet was solubilized using $100 \mu \mathrm{l} 33 \%$ (v/v) acetic acid. The absorbance of the solubilized crystal violet was measured at $492 \mathrm{~nm}$ using a Multiskan Ascent plate reader (Thermo Electron Corp.). Each experiment was carried out at least three times.

\begin{abstract}
Autolysis assays. Triton X-100-induced autolysis was assayed in exponential cultures grown to $\mathrm{OD}_{600} 2.0$ and in overnight cultures adjusted to $\mathrm{OD}_{600} 1.0$. Cells were pelleted by centrifugation and washed twice with $30 \mathrm{ml}$ cold PBS (Sigma). The cells were then resuspended in $30 \mathrm{ml} \mathrm{0.01 \%} \mathrm{(v/v)} \mathrm{Triton} \mathrm{X-100} \mathrm{(Sigma)} \mathrm{in} \mathrm{PBS} \mathrm{and}$ incubated at $37{ }^{\circ} \mathrm{C}$ with shaking. The $\mathrm{OD}_{600}$ was taken at regular time intervals. Results were normalized to time zero $\left(\mathrm{OD} t_{0}\right)$, i.e. percentage lysis $=\left[\left(\mathrm{OD}_{600} t_{0}-\mathrm{OD}_{600}\right.\right.$ at time $\left.\left.t\right) / \mathrm{OD}_{600} t_{0}\right] \times 100$. All results presented are the mean of at least three independent experiments.
\end{abstract}

Stationary phase lysis was measured by following the $\mathrm{OD}_{600}$ of cultures grown in BHI and BHI glucose media for $24 \mathrm{~h}$.

Bacterial adherence to hydrocarbon (BATH) assay. Cultures were grown with shaking in $\mathrm{BHI}$ and $\mathrm{BHI}$ glucose at $37^{\circ} \mathrm{C}$ to $\mathrm{OD}_{600}$ 2.0 before being washed twice in $1 \times$ PBS and resuspended in $4.5 \mathrm{ml}$ $1 \times$ PBS $\left(\mathrm{OD}_{600}\right.$ 1.0). As noted elsewhere (Rosenberg, 2006), the buffer in which the cells are suspended is an important variable in BATH assays, and in our experiments we found that different results were obtained using different commercial PBS buffers. We have used $1 \times$ Dulbecco's PBS (Oxoid) in these experiments. A $500 \mu$ l volume of $p$-xylene (Sigma) was added to the cell suspension and vortexed vigorously for $1 \mathrm{~min}$. After $20 \mathrm{~min}$ (to allow for phase separation) the percentage of cells (as determined spectrophotometrically at $\mathrm{OD}_{600}$ ) retained in the aqueous phase was measured. Each experiment was repeated three times.

Pellicle dispersal by sodium metaperiodate, proteinase $K$ and DNase I. Pellicle stability against proteinase $\mathrm{K}$ or sodium metaperiodate treatment was tested as described elsewhere (Mack et al., 1994; Rohde et al., 2005a), with the following modifications. Bacteria were grown at $37{ }^{\circ} \mathrm{C}$ overnight in $\mathrm{BHI}$ and $\mathrm{BHI}$ supplemented with $1 \%(\mathrm{w} /$ v) glucose in 96-well microtitre plates. Supernatants were carefully removed and each well was washed with $50 \mu \mathrm{l}$ distilled $\mathrm{H}_{2} \mathrm{O}$. Pellicles were treated with $50 \mu \mathrm{l} 10 \mathrm{mM}$ sodium metaperiodate (Fluka) in distilled $\mathrm{H}_{2} \mathrm{O}$ or $50 \mu \mathrm{l} 100 \mu \mathrm{g} \mathrm{ml}^{-1}$ proteinase $\mathrm{K}$ (Sigma) in distilled $\mathrm{H}_{2} \mathrm{O}$ for $2 \mathrm{~h}$ at $37^{\circ} \mathrm{C}$. The control wells contained $50 \mu$ distilled $\mathrm{H}_{2} \mathrm{O}$. Following incubation, each well was carefully washed with $50 \mu \mathrm{l}$ distilled $\mathrm{H}_{2} \mathrm{O}$ and dried for $1 \mathrm{~h}$ at $65{ }^{\circ} \mathrm{C}$ prior to staining with $0.4 \%$ (w/v) crystal violet. The $A_{492}$ of the adhered, stained pellicles was measured using a Multiskan Ascent plate reader. Each strain was tested at least three times and mean results are presented.

Strains were grown in media supplemented with $0.5 \mathrm{mg} \mathrm{ml}^{-1}$ DNase I (Sigma). DNase I was added at $t_{0}$ unless otherwise stated, and plates were incubated for $24 \mathrm{~h}$ at $37^{\circ} \mathrm{C}$ before pellicle formation was measured as described above.

PIA assays. PIA assays were performed as described previously (Holland et al., 2008). Briefly, $5 \mathrm{ml}$ of an exponential culture $\left(\mathrm{OD}_{600}\right.$ 2.0) was collected by centrifugation, resuspended in $250 \mu \mathrm{l} 0.5 \mathrm{M}$ EDTA and boiled for $5 \mathrm{~min}$. The cell debris was again centrifuged, and the supernatant was treated with $200 \mu \mathrm{g}$ proteinase $\mathrm{K}$ at $37{ }^{\circ} \mathrm{C}$ for $1 \mathrm{~h}$. The proteinase $\mathrm{K}$ was inactivated by boiling for $5 \mathrm{~min}$ and the samples were diluted as appropriate. To measure PIA in the culture supernatant, $500 \mu \mathrm{l}$ samples of supernatant were treated with proteinase $\mathrm{K}$ as described above. Samples were applied to a nitrocellulose membrane [pre-wetted in Tris-buffered saline (TBS)] using a vacuum blotter (Bio-Rad). The blots were dried, rewetted with TBS, and blocked for $1 \mathrm{~h}$ in $1 \%(\mathrm{w} / \mathrm{v})$ BSA. The primary antibody [1:5000 dilution of rabbit anti-PIA (a kind gift from Tomas Maira Litran and Gerald Pier, Brigham and Women's Hospital, Boston, MA, USA) in TBS-Tween-0.1\% BSA] was applied to the membrane for $1 \mathrm{~h}$. Horseradish peroxidase-linked anti-rabbit IgG secondary antibody ( $1: 5000$ dilution in TBS-Tween- $0.1 \%$ skimmed milk) was then incubated with the membrane for $1 \mathrm{~h}$. A chemiluminescence kit (Amersham) was used to generate light via the horseradish peroxidasecatalysed oxidation of luminol and detected using a Bio-Rad Fluor-S MAX charge-coupled device (CCD) camera system.

RNA purification. RNA purification was performed as described previously (Conlon et al., 2002) and the concentration was determined using a Nano-Drop spectrophotometer. Real-time RTPCR was performed on a LightCycler instrument using an RNA Amplification Kit SYBR Green I (Roche Biochemicals) following the manufacturer's recommended protocol (Holland et al., 2008). Reverse transcription was performed at $61{ }^{\circ} \mathrm{C}$ for $20 \mathrm{~min}$, followed by a denaturation step at $95{ }^{\circ} \mathrm{C}$ for $30 \mathrm{~s}$ and 35 amplification cycles of $95{ }^{\circ} \mathrm{C}$ for $2 \mathrm{~s}, 50{ }^{\circ} \mathrm{C}$ for $5 \mathrm{~s}$ and $72{ }^{\circ} \mathrm{C}$ for $8 \mathrm{~s}$. Melting curve analysis was performed at $45-95{ }^{\circ} \mathrm{C}$ (temperature transition, $0.1{ }^{\circ} \mathrm{C} \mathrm{s}^{-1}$ ) with stepwise fluorescence detection. For LightCycler RT-PCR, RelQuant software (Roche Biochemicals) was used to measure relative expression of target genes. The $\operatorname{gyrB}$ gene was used as an internal standard in real-time RT-PCR experiments. Each experiment was performed at least three times and mean data and SDs are presented. The primers used for RT-PCR are listed in Table 2.

Statistical analysis. Two-tailed, two-sample equal variance Student's $t$ tests (Microsoft Excel 2007) were used to determine statistically significant differences in assays performed during this study. A significant difference was indicated as a $P$ value $<0.05$.

\section{RESULTS}

\section{Mutation of the S. epidermidis tagO gene has pleiotropic effects, including impaired biofilm production and increased autolytic activity}

Allele replacement was used to construct a $\operatorname{tag} O$ deletion mutation in the biofilm-forming clinical isolate CSF41498. The TAGO1 mutant exhibited a range of phenotypic changes, including sensitivity to temperatures of greater than $40{ }^{\circ} \mathrm{C}$, resistance to bacteriophage $\mathrm{KC}$ and a significantly lower turbidity in overnight liquid cultures (data not shown). TAGO1 liquid cultures were characterized by macroscopic aggregates that rapidly settled at the bottom of the tube, indicative of enhanced intercellular aggregation (Fig. 1a). The TAGO1 mutant was unable to grow on Congo red agar (Fig. 1b) and interestingly exhibited a two-log increase in plasmid electroporation efficiency (Fig. 1c). Triton X-100-induced autolysis was also significantly increased in the mutant (Fig. 1d).

We used static 96-well plate assays to measure primary attachment and biofilm formation of TAGO1 grown in BHI media. Primary attachment to hydrophilic, tissue culturetreated polystyrene by TAGO1 cells was significantly 
(a)
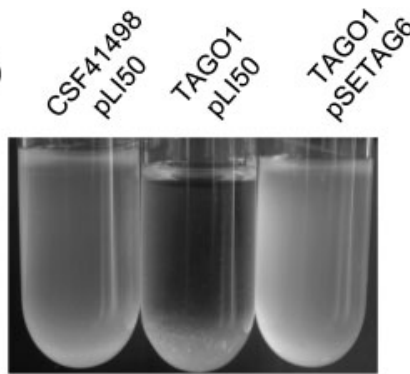

(c)

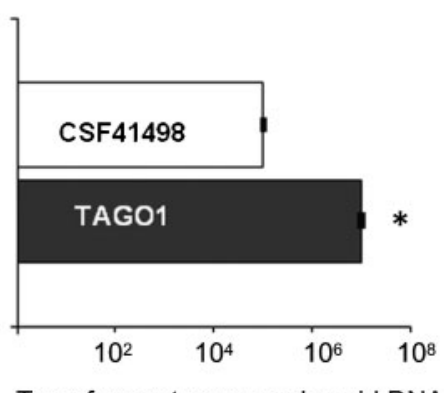

(b)

TAGO1 pSETAG6

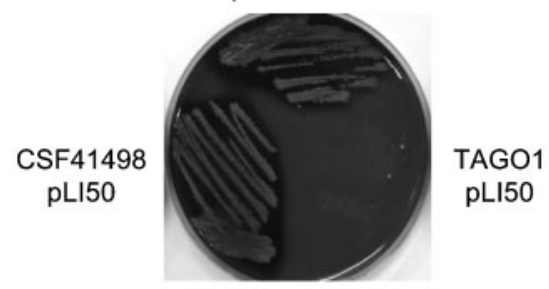

(d)

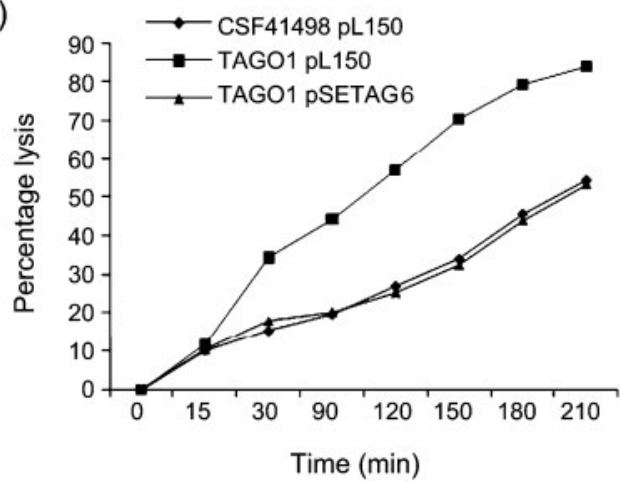

Fig. 1. (a) Multicellular behaviour of CSF41498 pLI50, TAGO1 pLI50 and TAGO1 pSETAG6 grown in BHI broth at $37{ }^{\circ} \mathrm{C}$ for $12 \mathrm{~h}$. TAGO1 pLI50 cultures form macroscopic aggregates which rapidly settle at the bottom of the tube. This phenotype can be fully complemented by the presence of pSETAG6. (b) Colony morphologies of CSF41498 pLI50, TAGO1 pLI50 and TAGO1 pSETAG6 on Congo red agar $\left(0.8 \mathrm{mg} \mathrm{m}^{-1}\right.$ ). (c) Electroporation efficiency of pLI50 into CSF41498 and TAGO1 expressed as the number of transformants per microgram of plasmid DNA. The asterisk indicates a significant difference $(P<0.05)$. (d) Triton $\mathrm{X}$-100-induced autolytic activity in exponential phase cultures of CSF41498 pLI50, TAGO1 pLI50 and TAGO1 pSETAG6 grown in BHI. Cells were resuspended in $0.01 \%$ Triton $\mathrm{X}-100$ and incubated at $37{ }^{\circ} \mathrm{C}$. The percentage lysis was determined by measuring the decrease in cell density $\left(\mathrm{OD}_{600}\right)$. Data presented represent the mean of at least three independent experiments.

impaired $(P<0.05)$ and could be complemented by the $\operatorname{tag} O$ gene (Fig. 2a). Biofilm production by TAGO1 on tissue culture-treated polystyrene after $24 \mathrm{~h}$ was significantly decreased $(P<0.05)$ and was also successfully complemented by $\operatorname{tagO}$ (Fig. 2b). Because hydrophobic interactions are important for cell interactions and biofilm development we used a BATH assay to measure the hydrophobicity of TAGO1 cells. This experiment revealed a significant increase in the hydrophobicity of TAGO1 compared with CSF41498 (Fig. 2c). This finding was consistent with the recent finding that an $S$. aureus tagO mutant is also more hydrophobic than its wild-type parent strain (Kohler et al., 2009). The increased surface hydrophobicity of TAGO1 cells may contribute to the observed changes in intercellular aggregation, attachment to polystyrene and biofilm production.

\section{Pellicle phenotype of the S. epidermidis tagO mutant}

Given that enhanced intercellular aggregation by TAGO1 cells appears to limit interactions with surfaces, we compared macroscopic cell clustering in BHI media supplemented with $\mathrm{NaCl}$ or glucose, both of which can promote biofilm development. The TAGO1 mutant was unable to grow in BHI media supplemented with $>1 \% \mathrm{NaCl}$ (data not shown), indicating an important role for WTA in osmotic stress tolerance. Growth of TAGO1 in BHI glucose was associated with reduced levels of stationary phase lysis (Supplementary Fig. S1). Consistent with this, Triton X-100induced autolytic activity was reduced in both the wild-type and TAGO1 strains grown in BHI glucose compared with BHI (Fig. 3a). Reduced autolytic activity in TAGO1 BHI glucose cultures correlated with the formation of a dense cell aggregate that settled to the bottom of the culture tube (Fig. 3b). Modified biofilm assays in which adherent cells were only gently washed to remove planktonic cells (see Methods for details) revealed that TAGO1 produced a pellicle in BHI glucose (Fig. 3b). This pellicle can be described as an aggregation of cells on the polystyrene surface that was easily detached during washing of the plate. We have chosen the term pellicle to be consistent with the nomenclature used by Vergara-Irigaray et al. (2008) in their description of an S. 

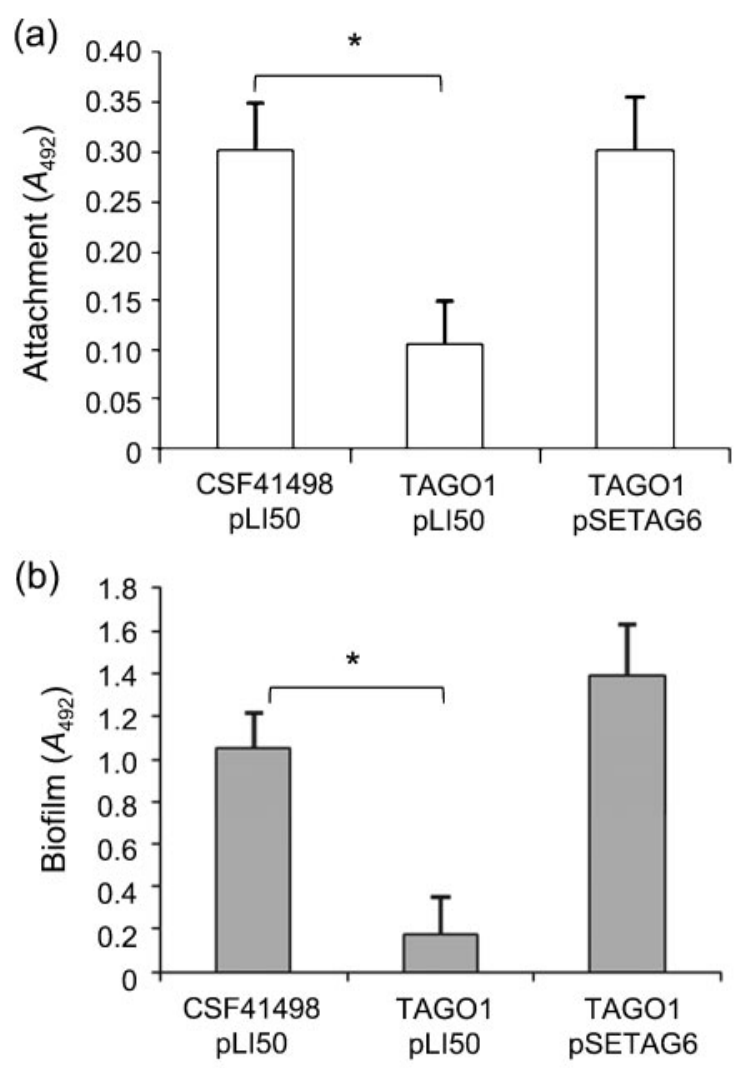

(c)

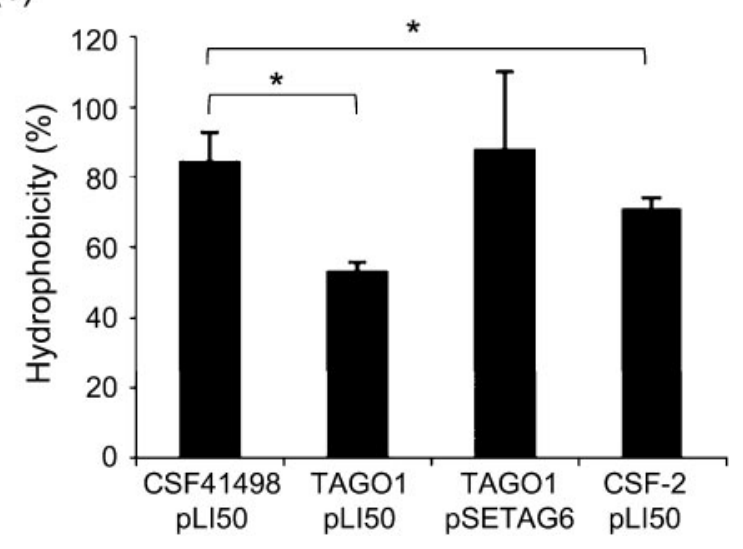

Fig. 2. Impact of tagO mutation on S. epidermidis biofilm formation. (a) Primary attachment phenotypes on tissue culture-treated polystyrene for CSF41498 pLI50, TAGO1 pLI50 and TAGO1 pSETAG6 grown to exponential phase in BHI. Attached cells remaining on the plate after washing were stained with crystal violet and $A_{492}$ was measured. Experiments were repeated three times and SDS are indicated (error bars). (b) Biofilm phenotypes of CSF41498 and TAGO1 strains complemented with pLI50 (control) and pSETAG6 (tagO). All strains were grown overnight at $37{ }^{\circ} \mathrm{C}$ in $\mathrm{BH}$. Data are the mean of at least three independent experiments and SDS are indicated (error bars). ( $a, b)$ Asterisk indicates a significant difference $(P<0.05)$. (c) Relative hydrophilicity of CSF41498 pLI50, TAGO1 pLI50, TAGO1 pSETAG6 and CSF-2 pLI50 cells. BATH assays were performed on cultures grown to $\mathrm{OD}_{600} 1.0$ in $\mathrm{BHI}$. Data are expressed as percentage relative hydrophilicity. Asterisks indicate significant differences $(P<0.05)$. aureus tagO mutant. In contrast, biofilms are tightly attached to the plate and can withstand vigorous washing. Growth in BHI glucose is associated with acidification of the culture medium (to $\sim \mathrm{pH}$ 5.5) (O'Neill et al., 2008). BHI acidified with acetic acid to $\mathrm{pH} 5.8$ also induced significant pellicle production by TAGO1 after $24 \mathrm{~h}(P<0.05)$ (Fig. 3d). Interestingly, time-course assays revealed the absence of pellicle production in the early stages of growth followed by significant pellicle formation after 12 and $24 \mathrm{~h}$ growth. This growth phase-dependent pellicle formation correlated with the acidification of the growth media over time (Fig. 3c). Taken together, these data indicated that pellicle formation by TAGO1 in BHI glucose media is induced by mild acid stress and is associated with reduced autolytic activity.

\section{Role of protein adhesins and eDNA in acid-induced TAGO1 pellicles}

TAGO1 pellicles were significantly dispersed by proteinase $\mathrm{K}(P<0.05)$ but unaffected by treatment with sodium metaperiodate (Fig. 4a), implicating protein adhesin(s) and not PIA in this phenotype. Glucose-induced TAGO1 pellicle formation was inhibited by the addition of DNase I to the growth medium at $t_{0}$ (Fig. $4 \mathrm{~b}$ ). In addition, pellicles formed by TAGO1 were also dispersed with DNase I added after 24 h growth (Fig. 4b). Heat-inactivated DNase I, used as a control, had no effect on pellicle formation or dispersal (data not shown). These data suggest that release of eDNA is required for formation of TAGO1 pellicles and that eDNA acts as a structural component of the TAGO1 pellicle matrix.

Ethanol precipitation was used to precipitate and visualize eDNA present in supernatants from exponential phase cultures of CSF41498, TAGO1 and the complemented mutant. Substantially more high-molecular-mass eDNA was recovered from TAGO1 culture supernatants compared with CSF41498 and the complemented mutant in both BHI and BHI glucose (Fig. 4c). This observation is consistent with eDNA playing an important role in TAGO1 pellicle formation, but suggests that it is not so important for wild-type biofilm formation.

For comparison, the role of PIA, protein adhesins and eDNA was also examined in the biofilms produced by the wild-type CSF41498. These experiments revealed that periodate significantly dispersed CSF41498 biofilms grown in BHI but not in BHI glucose (Fig. 4d), whereas proteinase $\mathrm{K}$ dispersed wild-type biofilms grown in BHI and BHI glucose (Fig. 4d). These data suggested that PIA may play a variable role in CSF41498 biofilm production and are supported by an earlier study which demonstrated that this strain is capable of producing PIA- and proteinaceous-type biofilms (Hennig et al., 2007). DNase I also dispersed CSF41498 biofilms grown in BHI but not in BHI glucose (Fig. 4d), indicating that eDNA can contribute to biofilm production in this strain under specific growth conditions. 


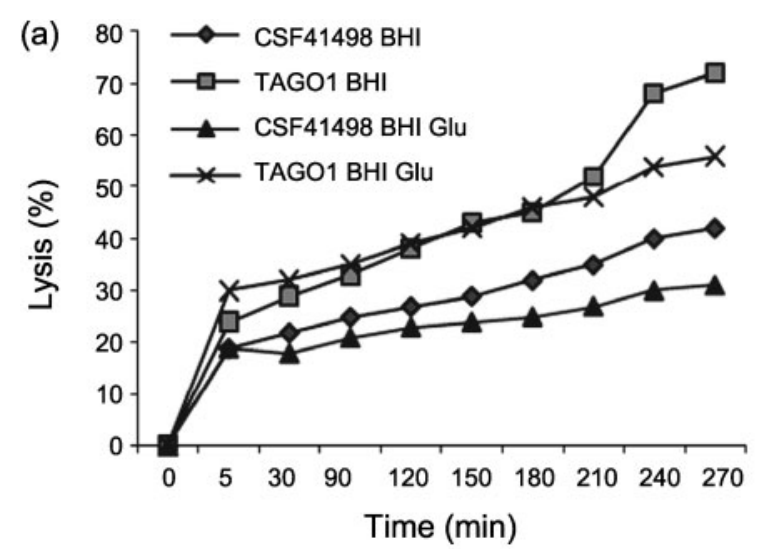

(b)

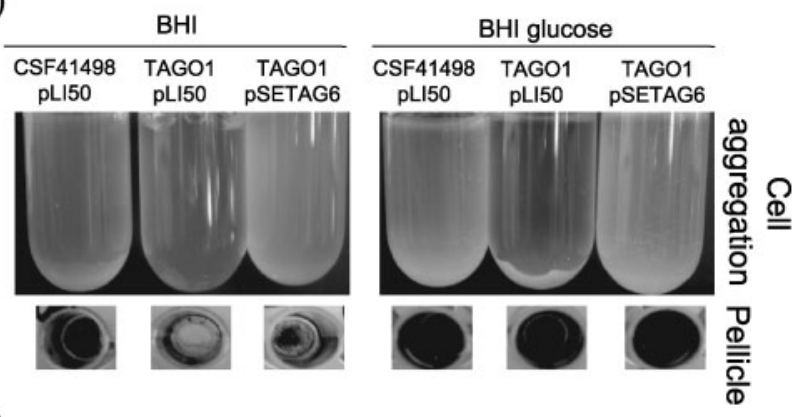

(c)

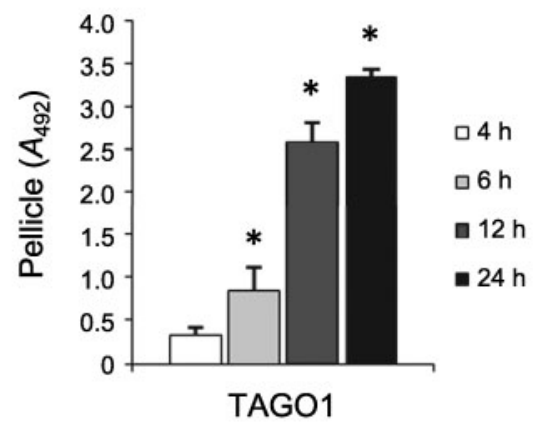

(d)

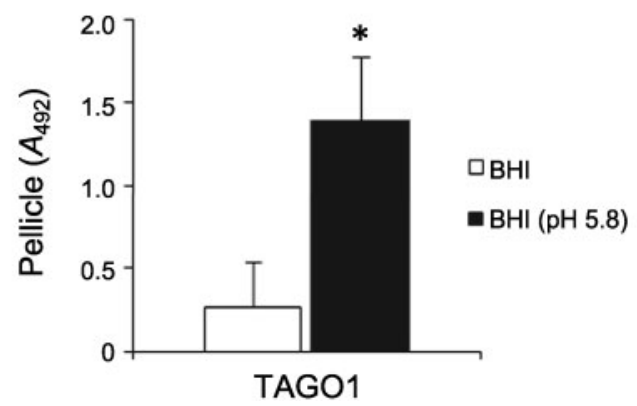

\section{Mutation of tagO reduces icaADBC expression and PIA production in S. epidermidis}

The increased autolytic activity and impaired primary attachment/biofilm phenotypes of the tagO mutant prompted us to examine the transcriptional activity of the major autolysin gene atlE and the icaADBC operon. Real-time RT-PCR revealed that atlE expression was similar in CSF41498 and TAGO1 grown in BHI or BHI glucose (data not shown). However, icaA transcript levels
Fig. 3. (a) Triton $\mathrm{X}-100$-induced autolytic activity in overnight cultures of CSF41498 and TAGO1 grown in BHI and BHI glucose. Cells were resuspended in $0.01 \%$ Triton X-100 and incubated at $37^{\circ} \mathrm{C}$. The percentage lysis was determined by measuring the decrease in cell density $\left(\mathrm{OD}_{600}\right)$. Data presented represent the mean of at least three independent experiments. (b) Comparison of cell aggregation in liquid culture and pellicle formation by CSF41498 pLI50, TAGO1 pLI50 and TAGO1 pSETAG6 grown in $\mathrm{BH}$ and $\mathrm{BHI}$ glucose for $24 \mathrm{~h}$ at $37^{\circ} \mathrm{C}$. TAGO1 pLI50 cultures undergo less stationary phase lysis in $\mathrm{BHI}$ glucose than in $\mathrm{BHI}$, leading to the formation of a pellicle at the base of the well. (c) Pellicle phenotype of TAGO1 grown in tissue culture-treated 96 -well plates for 4, 6, 12 and $24 \mathrm{~h}$ in BHI glucose at $37{ }^{\circ} \mathrm{C}$. Pellicles, which were very loosely attached to the polystyrene surface, were gently washed to remove planktonic cells before being dried and stained with crystal violet. Pellicle formation was measured at least three times and SDS are indicated (error bars). (d) Pellicle phenotype of TAGO1 grown in tissue culture-treated 96-well plates for $24 \mathrm{~h}$ in $\mathrm{BHI}$ and $\mathrm{BHI}$ adjusted to $\mathrm{pH} 5.8$ at $37^{\circ} \mathrm{C}$. Pellicle formation was measured at least three times and SDS are indicated (error bars). An asterisk indicates a significant difference $(P<0.05)$.

in TAGO1 were reduced approximately six- and 16-fold in BHI and BHI glucose, respectively, compared with the wild-type (Fig. 5a). Decreased icaA expression in TAGO1, in turn, corresponded to an approximately $2.5-$ and 6.6fold increase in icaR transcription in BHI and BHI glucose, respectively, compared with CSF41498 (Fig. 5b). Growth of CSF41498 and the complemented mutant in BHI glucose was associated with a 2.8 -fold increase in icaA expression and a 1.5-fold decrease in icaR expression (Fig. 5a, b), suggesting that mild acid stress may activate ica operon expression via repression of the negative regulator icaR. Immuno-dot blots revealed that deletion of tagO led to a reduction in PIA levels in both whole-cell extracts and supernatants from cultures grown in BHI and $\mathrm{BHI}$ glucose media (Fig. 5c). To examine whether the reduced PIA production by TAGO1 was involved in increased cell surface hydrophobicity, we compared CSF41498 and its isogenic ica mutant CSF-2 using the BATH technique. This revealed that surface hydrophobicity was increased in CSF-2 (Fig. 2c), indicating that extracellular PIA also influences surface hydrophobicity in this strain. Taken together, these data reveal that mutation of $\operatorname{tagO}$ is associated with activation of $i c a R$, decreased icaADBC expression and reduced PIA production. In addition, diminished PIA levels and the loss of WTA combine to increase surface hydrophobicity. Thus, these data indicate that the biofilm-negative phenotype of the tagO mutant can be attributed to impaired PIA production and increased surface hydrophobicity.

\section{DISCUSSION}

Deletion of tagO in S. epidermidis had pleiotropic effects which were consistent with the loss of WTA. These included increased sensitivity to osmotic stress and 
(a)

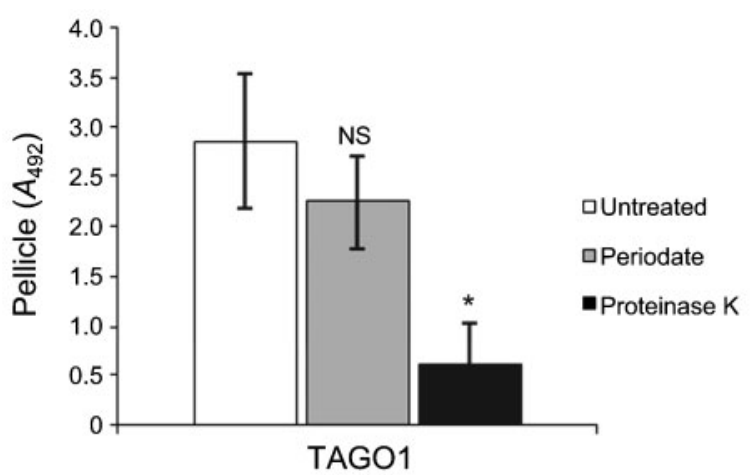

(b)

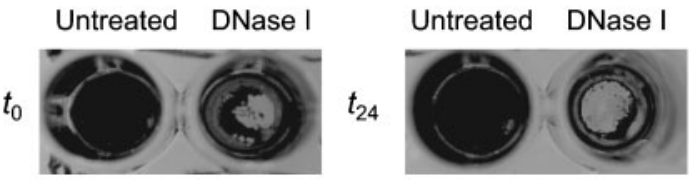

(c)
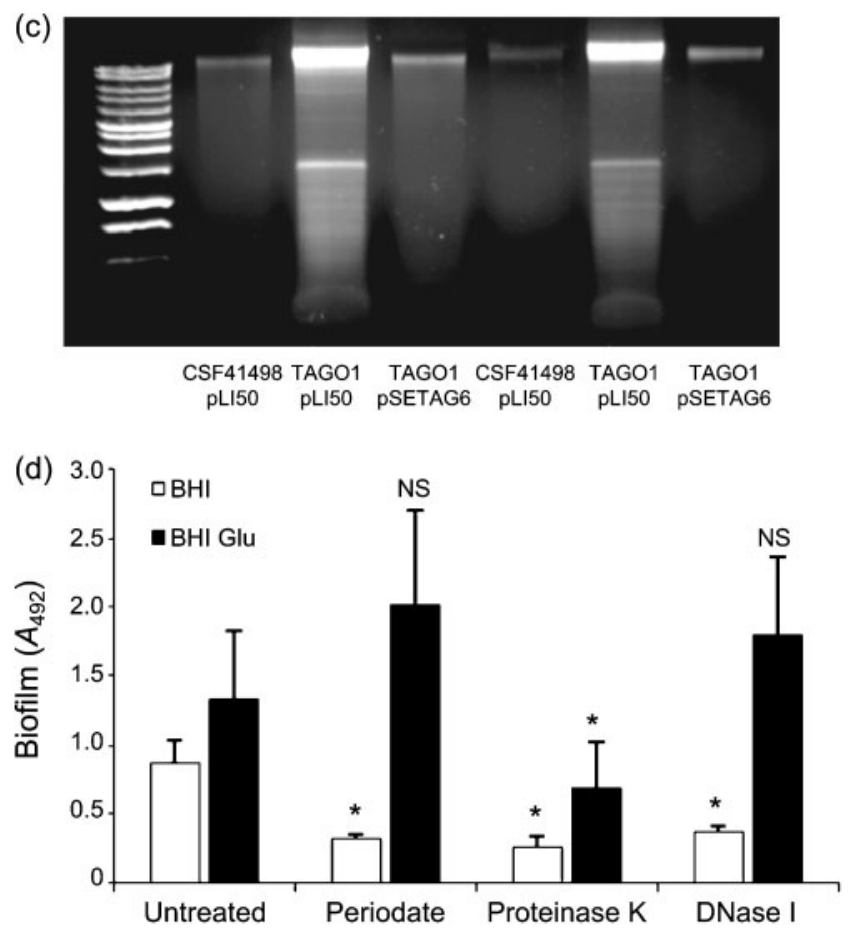

Fig. 4. (a) Dispersal of TAGO1 pellicles with sodium metaperiodate and proteinase $\mathrm{K}$ added to $\mathrm{BHI}$ glucose cultures after $24 \mathrm{~h}$ growth compared with an untreated control. The asterisk indicates a significant difference $(P<0.05)$; NS, not significant. (b) Dispersal of TAGO1 pellicles with DNase I $\left(0.5 \mathrm{mg} \mathrm{ml}^{-1}\right)$ added to $\mathrm{BHI}$ glucose cultures at $t_{0}(\mathrm{O} \mathrm{h})$ or after $24 \mathrm{~h}$ growth compared with untreated controls. (c) Comparative analysis of eDNA recovered from culture supernatants of CSF41498 pLI50, TAGO1 pLI50 and TAGO1 pSETAG6 cultures grown to $\mathrm{OD}_{600} 2.0$ in $\mathrm{BHI}$ and $\mathrm{BHI}$ glucose. eDNA was visualized after electrophoresis on a $1 \%$ agarose gel. (d) Dispersal of CSF41498 biofilms with sodium metaperiodate, proteinase $\mathrm{K}$ and DNase I $\left(0.5 \mathrm{mg} \mathrm{ml}^{-1}\right)$ added to $\mathrm{BHI}$ and $\mathrm{BHI}$ glucose cultures after $24 \mathrm{~h}$ growth compared with biofilm production in an untreated control. Asterisks indicate significant differences $(P<0.05)$; NS, not significant. temperatures $>40{ }^{\circ} \mathrm{C}$, increased susceptibility to Congo red, resistance to bacteriophage infection, macroscopic clumping during growth in liquid culture media and increased autolytic activity. Increased sensitivity to Congo red, which is known to be toxic, may be due to increased cell envelope penetration. A recent study of $S$. aureus found that increased sensitivity to Congo red in an msrR mutant was associated with reduced levels of WTA (Hübscher $e t$ al., 2009). To our knowledge, this study is the first report of increased plasmid electroporation efficiencies in a $\operatorname{tagO}$ mutant and perhaps suggests that changes in WTA composition influence genetic exchange and transfer of antibiotic and virulence genes among staphylococci. In the laboratory, $\operatorname{tag} O$ mutants may also have potential as a tool in genetic manipulation of $S$. epidermidis strains, which are notoriously difficult to transform.

Increased autolytic activity in TAGO1 was consistent with earlier studies of $S$. aureus tagO and $d l t A$ mutants (Gross et al., 2001; Koprivnjak et al., 2008; Maki et al., 1994; Vergara-Irigaray et al., 2008). The mechanistic basis for increased autolytic activity in WTA mutants has recently been described. Schlag et al. (2010) have revealed that WTA prevents binding of the major autolysin Atl to the cell wall and that binding of the Atl-derived amidase enzyme is increased at the cross wall region, presumably due to a lower WTA concentration. Thus, in the absence of WTA, increased binding and activity of Atl-derived peptidoglycan hydrolases leads to increased rates of autolysis.

The tagO mutant was biofilm-negative, a phenotype which correlated with increased cell surface hydrophobicity, impaired primary attachment, increased autolytic activity and defective PIA production. Deletion of tagO in S. aureus has also been shown to impair biofilm formation, although it does not affect PIA expression or anchoring to the cell wall (Gross et al., 2001; Vergara-Irigaray et al., 2008). Decreased PIA production was due, at least in part, to activation of the transcription of icaR, which encodes a negative regulator of the ica operon (Conlon et al., 2002), with the concomitant repression of the icaADBC operon. Interestingly, Knobloch et al. (2004) have reported that activation of the alternative sigma factor $\sigma^{\mathrm{B}}$ results in repression of icaR and increased icaADBC transcription. Thus, although it remains to be determined precisely how the transcriptional activity of the ica locus is altered in the tagO mutant, one possible mechanism is that cell surface changes associated with loss of WTA influence $\sigma^{\mathrm{B}}$-dependent $i c a A D B C$ regulation.

Under mild acidic growth conditions in BHI glucose media, the $S$. epidermidis TAGO1 mutant produced a pellicle, which we define here as an aggregation of cells easily detached from a surface. Pellicle formation by TAGO1 in BHI glucose correlated with reduced levels of TAGO1 stationary phase lysis as a result of decreased autolytic activity. Thus, higher cell densities in BHI glucose cultures correlate with pellicle formation. An increased tendency for cell aggregation and pellicle formation has 

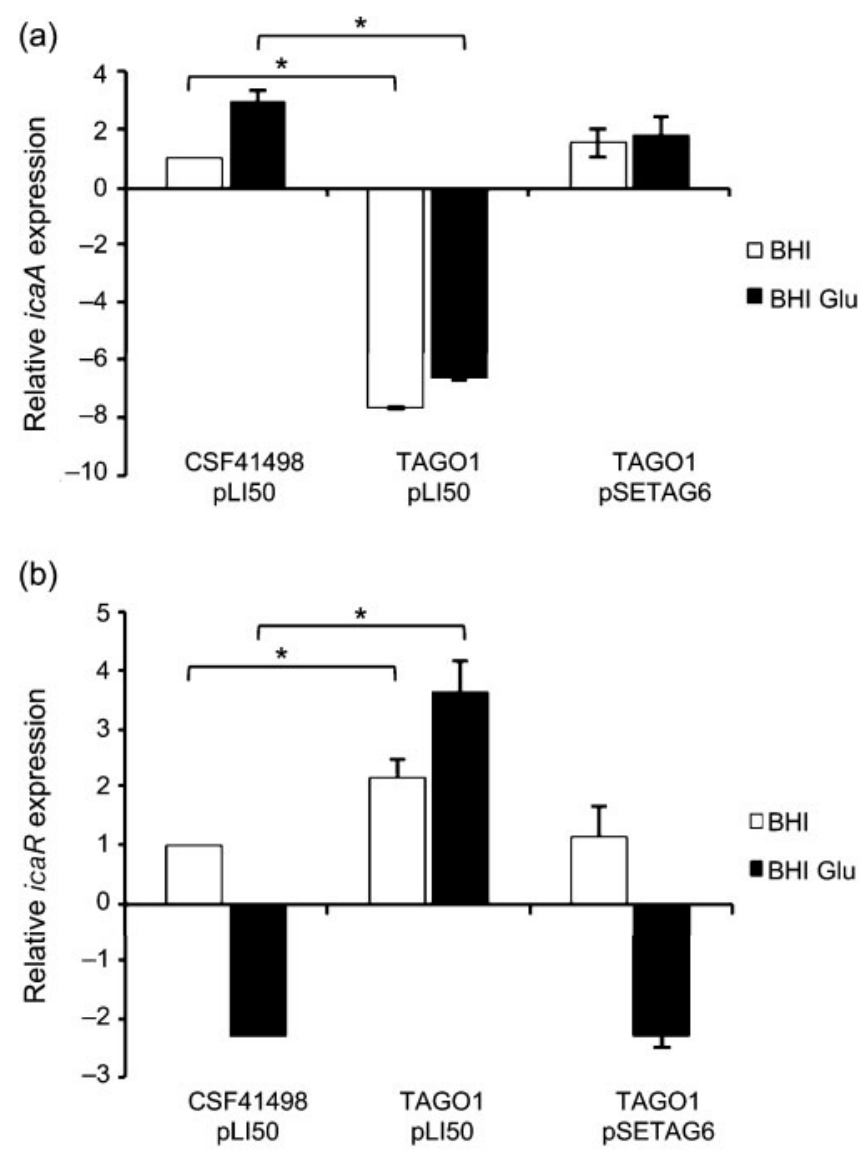

(c)

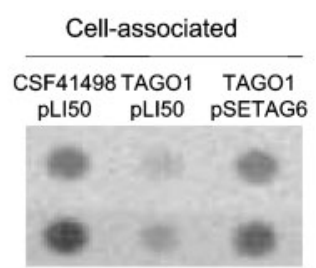

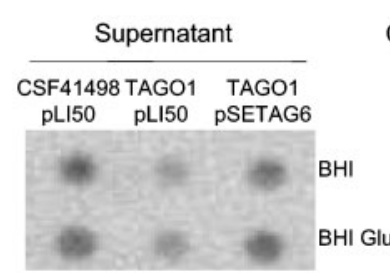

Controls

CSF41498 (PIA-positive) CSF-2 (PIA-negative)
Fig. 5. Comparative measurements of ica $A$ (a) and icaR (b) transcription by real-time RT-PCR in CSF41498 pLI50, TAGO1 pLI50 and TAGO1 pSETAG6. Total RNA was extracted from cultures grown at $37{ }^{\circ} \mathrm{C}$ to $\mathrm{OD}_{600} 2.0$ in $\mathrm{BHI}$ and $\mathrm{BHI}$ glucose. RelQuant software (Roche) was used to compare the relative expression of ica $A$ and ica $R$ transcript levels with respect to the constitutively expressed gyr $B$ gene. Transcript levels of ica $A$ and icaR in strains grown in $\mathrm{BHI}$ and $\mathrm{BHI}$ glucose were compared with transcript levels in CSF41498 pLI50 grown in $\mathrm{BHI}$, which was assigned a value of 1 . Data represent the mean of three independent experiments and SDS are indicated (error bars). Asterisks indicate significant differences $(P<0.05)$. (c) Immunoblots of PIA production in whole-cell lysates and supernatants of CSF41498 pLI50, TAGO1 pLI50 and TAGO1 pSETAG6 cultures grown to $\mathrm{OD}_{600} 2.0$ in $\mathrm{BHI}$ and $\mathrm{BHI}$ glucose. PIA immunoblots of whole-cell extracts of wildtype CSF41498 and its isogenic PIA-negative derivative CSF-2 are also shown. also been reported in an $S$. aureus $\Delta \operatorname{tag} O$ mutant grown in tryptone soya media supplemented with glucose (VergaraIrigaray et al., 2008). In contrast to TAGO1 pellicles, CSF41498 biofilms are tightly attached to the surface and can withstand vigorous washing. Acid-induced TAGO1 pellicles were dispersed with DNase I and proteinase $\mathrm{K}$ but not sodium metaperiodate, implicating both protein and eDNA adhesins and not PIA in this phenotype. Autolytic activity can also influence cell aggregation by controlling the release of eDNA, which has recently been shown to play a role in early S. epidermidis biofilm formation (Qin et al., 2007). Our analysis revealed that increased autolytic activity in TAGO1 during the exponential phase of growth correlated with increased release of eDNA, and that eDNA was important for pellicle formation in BHI glucose. However, eDNA levels in exponential phase culture supernatants of TAGO1 grown in BHI and BHI glucose were similar, suggesting that eDNA alone cannot explain enhanced pellicle production by TAGO1 in BHI glucose. Consistent with this, acid-induced TAGO1 pellicles were also significantly dispersed with proteinase $\mathrm{K}$, implicating a protein adhesin(s) in this phenotype. One candidate for this adhesin is the accumulation-associated protein (Aap), which has previously been implicated in both S. epidermidis (Rohde et al., 2005b) and S. aureus (Corrigan et al., 2007) biofilm production. Significantly, a CSF41498 icaC: : IS256 mutant which spontaneously switches to PIA-independent biofilm production is associated with upregulation of aap transcription (Hennig et al., 2007). However, our data revealed that aap expression was unaffected in the TAGO1 mutant grown in BHI or BHI glucose. Staphylococcal surface proteins may also be anchored to the cell wall via interactions with teichoic acids (Navarre \& Schneewind, 1999). Although earlier analysis of WTA-deficient mutants has revealed only minor effects on cell surface proteins (Gross et al., 2001; Weidenmaier et al., 2004), electron 
microscopy of $S$. aureus tagO mutants reveals a rough outer surface compared with the wild-type (Koprivnjak et al., 2008; Schlag et al., 2010), possibly as a result of cell wall disintegration (Schlag et al., 2010). Therefore it is also possible that cell surface physical changes in strains lacking WTA may be accompanied by the unmasking of an acidactivated cell wall protein(s) which has not been previously implicated in cell aggregation.

Overall, our data reveal that WTA are required for $S$. epidermidis biofilm formation and that mutation of $\operatorname{tag} O$ is associated with increased cell surface hydrophobicity and repression of icaADBC and PIA expression. Interestingly, enhanced autolytic activity in the TAGO1 mutant is associated with increased eDNA release, which, together with protein adhesins, promotes the formation of a pellicle. Unlike a biofilm, this pellicle is only loosely attached to surfaces, indicating that enhanced intercellular aggregation/pellicle formation is accompanied by a reduced capacity to attach to surfaces and form biofilms.

\section{ACKNOWLEDGEMENTS}

This study was funded by the Irish Health Research Board (J. P. O'G.) and the Irish Research Council for Science Engineering and Technology (L. M.H. and B. C.). We are indebted to M. Gomelsky for ongoing support and critical comments on this manuscript. We also thank P. Fey for useful discussion on the findings of this study, T. Pitt for phage KC and W. Ziebuhr for strain CSF-2; rabbit anti-PIA serum was a gift from T. Maira Litran and G. B. Pier (see main text). We are grateful to C. Pozzi, E. O'Neill, P. Houston, S. Rowe, E. dePoire and E. Waters for their support and advice over the course of this study.

\section{REFERENCES}

Arnaud, M., Chastanet, A. \& Debarbouille, M. (2004). New vector for efficient allelic replacement in naturally nontransformable, low-GCcontent, Gram-positive bacteria. Appl Environ Microbiol 70, 68876891.

Brown, S., Zhang, Y. H. \& Walker, S. (2008). A revised pathway proposed for Staphylococcus aureus wall teichoic acid biosynthesis based on in vitro reconstitution of the intracellular steps. Chem Biol 15, 12-21.

Brückner, R. (1997). Gene replacement in Staphylococcus carnosus and Staphylococcus xylosus. FEMS Microbiol Lett 151, 1-8.

Calamita, H. G. \& Doyle, R. J. (2002). Regulation of autolysins in teichuronic acid-containing Bacillus subtilis cells. Mol Microbiol 44, 601-606.

Conlon, K. M., Humphreys, H. \& O'Gara, J. P. (2002). icaR encodes a transcriptional repressor involved in environmental regulation of ica operon expression and biofilm formation in Staphylococcus epidermidis. J Bacteriol 184, 4400-4408.

Corrigan, R. M., Rigby, D., Handley, P. \& Foster, T. J. (2007). The role of Staphylococcus aureus surface protein SasG in adherence and biofilm formation. Microbiology 153, 2435-2446.

Eckhart, L., Fischer, H., Barken, K. B., Tolker-Nielsen, T. \& Tschachler, E. (2007). DNase1L2 suppresses biofilm formation by Pseudomonas aeruginosa and Staphylococcus aureus. Br J Dermatol 156, $1342-1345$.
Endl, J., Seidl, H. P., Fiedler, F. \& Schleifer, K. H. (1983). Chemical composition and structure of cell wall teichoic acids of staphylococci. Arch Microbiol 135, 215-223.

Gertz, S., Engelmann, S., Schmid, R., Ohlsen, K., Hacker, J. \& Hecker, M. (1999). Regulation of sigmaB-dependent transcription of sigB and asp23 in two different Staphylococcus aureus strains. Mol Gen Genet 261, 558-566.

Gross, M., Cramton, S. E., Gotz, F. \& Peschel, A. (2001). Key role of teichoic acid net charge in Staphylococcus aureus colonization of artificial surfaces. Infect Immun 69, 3423-3426.

Handke, L. D., Conlon, K. M., Slater, S. R., Elbaruni, S., Fitzpatrick, F., Humphreys, H., Giles, W. P., Rupp, M. E., Fey, P. D. \& O'Gara, J. P. (2004). Genetic and phenotypic analysis of biofilm phenotypic variation in multiple Staphylococcus epidermidis isolates. J Med Microbiol 53, 367-374.

Heilmann, C., Hussain, M., Peters, G. \& Gotz, F. (1997). Evidence for autolysin-mediated primary attachment of Staphylococcus epidermidis to a polystyrene surface. Mol Microbiol 24, 1013-1024.

Hennig, S., Nyunt Wai, S. \& Ziebuhr, W. (2007). Spontaneous switch to PIA-independent biofilm formation in an ica-positive Staphylococcus epidermidis isolate. Int J Med Microbiol 297, 117-122.

Holland, L. M., O’Donnell, S. T., Ryjenkov, D. A., Gomelsky, L., Slater, S. R., Fey, P. D., Gomelsky, M. \& O'Gara, J. P. (2008). A staphylococcal GGDEF domain protein regulates biofilm formation independently of cyclic dimeric GMP. J Bacteriol 190, 5178-5189.

Hübscher, J., McCallum, N., Sifri, C. D., Majcherczyk, P. A., Entenza, J. M., Heusser, R., Berger-Bachi, B. \& Stutzmann Meier, P. (2009). MsrR contributes to cell surface characteristics and virulence in Staphylococcus aureus. FEMS Microbiol Lett 295, 251-260.

Hughes, A. H., Hancock, I. C. \& Baddiley, J. (1973). The function of teichoic acids in cation control in bacterial membranes. Biochem $J$ 132, 83-93.

Hyyrylainen, H. L., Vitikainen, M., Thwaite, J., Wu, H., Sarvas, M., Harwood, C. R., Kontinen, V. P. \& Stephenson, K. (2000). D-Alanine substitution of teichoic acids as a modulator of protein folding and stability at the cytoplasmic membrane/cell wall interface of Bacillus subtilis. J Biol Chem 275, 26696-26703.

Izano, E. A., Amarante, M. A., Kher, W. B. \& Kaplan, J. B. (2008). Differential roles of poly- $N$-acetylglucosamine surface polysaccharide and extracellular DNA in Staphylococcus aureus and Staphylococcus epidermidis biofilms. Appl Environ Microbiol 74, 470-476.

Khan, S. A. \& Novick, R. P. (1983). Complete nucleotide sequence of pT181, a tetracycline-resistance plasmid from Staphylococcus aureus. Plasmid 10, 251-259.

Knobloch, J. K., Jager, S., Horstkotte, M. A., Rohde, H. \& Mack, D. (2004). RsbU-dependent regulation of Staphylococcus epidermidis biofilm formation is mediated via the alternative sigma factor $\sigma^{\mathrm{B}}$ by repression of the negative regulator gene icaR. Infect Immun 72, 38383848.

Kohler, T., Weidenmaier, C. \& Peschel, A. (2009). Wall teichoic acid protects Staphylococcus aureus against antimicrobial fatty acids from human skin. J Bacteriol 191, 4482-4484.

Koprivnjak, T., Weidenmaier, C., Peschel, A. \& Weiss, J. P. (2008). Wall teichoic acid deficiency in Staphylococcus aureus confers selective resistance to mammalian group IIA phospholipase $\mathrm{A}_{2}$ and human $\beta$ defensin 3. Infect Immun 76, 2169-2176.

Kreiswirth, B. N., Lofdahl, S., Betley, M. J., O'Reilly, M., Schlievert, P. M., Bergdoll, M. S. \& Novick, R. P. (1983). The toxic shock syndrome exotoxin structural gene is not detectably transmitted by a prophage. Nature 305, 709-712.

Lambert, P. A., Hancock, I. C. \& Baddiley, J. (1977). Occurrence and function of membrane teichoic acids. Biochim Biophys Acta 472, 1-12. 
Lazarevic, V., Abellan, F. X., Moller, S. B., Karamata, D. \& Mauël, C. (2002). Comparison of ribitol and glycerol teichoic acid genes in Bacillus subtilis W23 and 168: identical function, similar divergent organization, but different regulation. Microbiology 148, 815-824.

Lee, C. Y., Buranen, S. L. \& Ye, Z. H. (1991). Construction of singlecopy integration vectors for Staphylococcus aureus. Gene 103, 101105.

Mack, D. (1999). Molecular mechanisms of Staphylococcus epidermidis biofilm formation. J Hosp Infect 43 ((Suppl), ), S113-S125.

Mack, D., Nedelmann, M., Krokotsch, A., Schwarzkopf, A., Heesemann, J. \& Laufs, R. (1994). Characterization of transposon mutants of biofilm-producing Staphylococcus epidermidis impaired in the accumulative phase of biofilm production: genetic identification of a hexosamine-containing polysaccharide intercellular adhesin. Infect Immun 62, 3244-3253.

Maki, H., Yamaguchi, T. \& Murakami, K. (1994). Cloning and characterization of a gene affecting the methicillin resistance level and the autolysis rate in Staphylococcus aureus. J Bacteriol 176, 4993-5000.

Mann, E. E., Rice, K. C., Boles, B. R., Endres, J. L., Ranjit, D., Chandramohan, L., Tsang, L. H., Smeltzer, M. S., Horswill, A. R. \& Bayles, K. W. (2009). Modulation of eDNA release and degradation affects Staphylococcus aureus biofilm maturation. PLoS ONE 4, e5822.

Mauël, C., Young, M. \& Karamata, D. (1991). Genes concerned with synthesis of poly(glycerol phosphate), the essential teichoic acid in Bacillus subtilis strain 168, are organized in two divergent transcription units. J Gen Microbiol 137, 929-941.

Mauël, C., Bauduret, A., Chervet, C., Beggah, S. \& Karamata, D. (1995). In Bacillus subtilis 168, teichoic acid of the cross-wall may be different from that of the cylinder: a hypothesis based on transcription analysis of tag genes. Microbiology 141, 2379-2389.

Navarre, W. W. \& Schneewind, O. (1999). Surface proteins of Grampositive bacteria and mechanisms of their targeting to the cell wall envelope. Microbiol Mol Biol Rev 63, 174-229.

Neuhaus, F. C. \& Baddiley, J. (2003). A continuum of anionic charge: structures and functions of D-alanyl-teichoic acids in Gram-positive bacteria. Microbiol Mol Biol Rev 67, 686-723.

Novick, R. P. (1991). Genetic systems in staphylococci. Methods Enzymol 204, 587-636.

O'Neill, E., Pozzi, C., Houston, P., Humphreys, H., Robinson, D. A., Loughman, A., Foster, T. J. \& O'Gara, J. P. (2008). A novel Staphylococcus aureus biofilm phenotype mediated by the fibronectin-binding proteins, FnBPA and FnBPB. J Bacteriol 190, 3835-3850.

Qian, Z., Yin, Y., Zhang, Y., Lu, L., Li, Y. \& Jiang, Y. (2006). Genomic characterization of ribitol teichoic acid synthesis in Staphylococcus aureus: genes, genomic organization and gene duplication. $B M C$ Genomics 7, 74.

Qin, Z., Ou, Y., Yang, L., Zhu, Y., Tolker-Nielsen, T., Molin, S. \& Qu, D. (2007). Role of autolysin-mediated DNA release in biofilm formation of Staphylococcus epidermidis. Microbiology 153, 2083-2092.

Rice, K. C., Mann, E. E., Endres, J. L., Weiss, E. C., Cassat, J. E., Smeltzer, M. S. \& Bayles, K. W. (2007). The cidA murein hydrolase regulator contributes to DNA release and biofilm development in Staphylococcus aureus. Proc Natl Acad Sci U S A 104, 8113-8118.

Rohde, H., Burdelski, C., Bartscht, K., Hussain, M., Buck, F., Horstkotte, M. A., Knobloch, J. K., Heilmann, C., Herrmann, M. \& Mack, D. (2005a). Induction of Staphylococcus epidermidis biofilm formation via proteolytic processing of the accumulation-associated protein by staphylococcal and host proteases. Mol Microbiol 55, 1883 1895.

Rohde, H., Burdelski, C., Bartscht, K., Hussain, M., Buck, F., Horstkotte, M. A., Knobloch, J. K., Heilmann, C., Herrmann, M. \& Mack, D. (2005b). Induction of Staphylococcus epidermidis biofilm formation via proteolytic processing of the accumulation-associated protein by staphylococcal and host proteases. Mol Microbiol 55, 18831895.

Rosenberg, M. (2006). Microbial adhesion to hydrocarbons: twentyfive years of doing MATH. FEMS Microbiol Lett 262, 129-134.

Sadovskaya, I., Vinogradov, E., Li, J. \& Jabbouri, S. (2004). Structural elucidation of the extracellular and cell-wall teichoic acids of Staphylococcus epidermidis RP62A, a reference biofilm-positive strain. Carbohydr Res 339, 1467-1473.

Sadovskaya, I., Vinogradov, E., Flahaut, S., Kogan, G. \& Jabbouri, S. (2005). Extracellular carbohydrate-containing polymers of a model biofilm-producing strain, Staphylococcus epidermidis RP62A. Infect Immun 73, 3007-3017.

Schlag, M., Biswas, R., Krismer, B., Kohler, T., Zoll, S., Yu, W., Schwarz, H., Peschel, A. \& Gotz, F. (2010). Role of staphylococcal wall teichoic acid in targeting the major autolysin Atl. Mol Microbiol 75, 864-873.

Soldo, B., Lazarevic, V. \& Karamata, D. (2002). $\operatorname{tagO}$ is involved in the synthesis of all anionic cell-wall polymers in Bacillus subtilis 168. Microbiology 148, 2079-2087.

Swoboda, J. G., Campbell, J., Meredith, T. C. \& Walker, S. (2010). Wall teichoic acid function, biosynthesis, and inhibition. ChemBioChem 11, 35-45.

Vergara-Irigaray, M., Maira-Litran, T., Merino, N., Pier, G. B., Penades, J. R. \& Lasa, I. (2008). Wall teichoic acids are dispensable for anchoring the PNAG exopolysaccharide to the Staphylococcus aureus cell surface. Microbiology 154, 865-877.

Vinogradov, E., Sadovskaya, I., Li, J. \& Jabbouri, S. (2006). Structural elucidation of the extracellular and cell-wall teichoic acids of Staphylococcus aureus MN8m, a biofilm forming strain. Carbohydr Res 341, 738-743.

Weidenmaier, C. \& Peschel, A. (2008). Teichoic acids and related cell-wall glycopolymers in Gram-positive physiology and host interactions. Nat Rev Microbiol 6, 276-287.

Weidenmaier, C., Kokai-Kun, J. F., Kristian, S. A., Chanturiya, T., Kalbacher, H., Gross, M., Nicholson, G., Neumeister, B., Mond, J. J. \& Peschel, A. (2004). Role of teichoic acids in Staphylococcus aureus nasal colonization, a major risk factor in nosocomial infections. Nat Med 10, 243-245.

Edited by: J. Lindsay 